\title{
Fabrication of Robust Superhydrophobic Bamboo Based on ZnO Nanosheet Networks with Improved Water-, UV-, and Fire-Resistant Properties
}

\author{
Jingpeng Li, Qingfeng Sun, Qiufang Yao, Jin Wang, Shenjie Han, and Chunde Jin \\ School of Engineering, Zhejiang Agricultural and Forestry University, Linian 311300, China \\ Correspondence should be addressed to Chunde Jin; zafujincd@163.com
}

Received 12 August 2014; Accepted 2 September 2014

Academic Editor: Ivan C. K. Tan

Copyright (c) 2015 Jingpeng Li et al. This is an open access article distributed under the Creative Commons Attribution License, which permits unrestricted use, distribution, and reproduction in any medium, provided the original work is properly cited.

Bamboo with water-resistant, UV-resistant, and fire-resistant properties was desirable in modern society. In this paper, the original bamboo was firstly treated with $\mathrm{ZnO}$ sol and then hydrothermally the $\mathrm{ZnO}$ nanosheet networks grow onto the bamboo surface and subsequently modified with fluoroalkyl silane (FAS-17). The FAS-17 treated bamboo substrate exhibited not only robust superhydrophobicity with a high contact angle of $161^{\circ}$ but also stable repellency towards simulated acid rain $(\mathrm{pH}=3)$ with a contact angle of $152^{\circ}$. Except for its robust superhydrophobicity, such a bamboo also presents superior water-resistant, UV-resistant, and fire-resistant properties.

\section{Introduction}

Bamboo is one of the most important nontimber forest products in the world $[1,2]$. More than 1 billion people are living in bamboo houses, and the livelihoods of 2.5 billion people depend on this resource, making the bamboo increasingly be recognized as an environmental-friendly and cost-effective wood substitute [3]. As a fast-growing lignocelluloses material with high strength and surface hardness, easy machinability, and local availability, bamboo is widely used in the traditional applications, such as furniture, construction, pulping, and handcrafts [4-6]. However, when exposed in an outdoor environment, bamboo shows bad decay-resistance without protective treatment that would be attacked by fungi and insects and degraded caused by moisture, air, acid rain, and sunlight and thus shortens its service life and also reduces its value $[7,8]$. To overcome this problem and enhance the economic value of bamboo products, it is necessary to develop a protective treatment for bamboo materials. In the previous studies, there were several approaches to improve water-repellency, fire-resistance, and UV-resistance of cellulose-based materials [9-14], for example, immersion-diffusion or vacuum-impregnation with preservatives, heating, dipping, soaking, brushing paint, and surface modification.

Among these, surface modification has been used to improve the ultraviolet stability of bamboo, change the surface energy of bamboo (reduce wetting by water and/or improve compatibility with coatings or matrix materials), and improve the bonding between bamboo surfaces and inorganic materials. In the past decade, the modifications by using of inorganic materials, such as $\mathrm{ZnO}, \mathrm{SiO}_{2}, \mathrm{TiO}_{2}$, and $\mathrm{CaCO}_{3}$ through sol-gel or hydrothermal synthesis have been devoted to reach this goal $[15,16]$. Nowadays, as one of the most interesting multifunctional material, $\mathrm{ZnO}$ has a promising application in various fields of solar cells [17], displays [18], gas sensors [19], varistors [20], piezoelectric devices [21], photodiodes [22], UV light emitting devices, and a photostabilizer [23]. Thus, after surface modification, the bamboo-inorganic composites could be attached with photostability and antibacterial properties [16], and the coating of inorganic materials may also impart new properties such as superhydrophobicity, UV-resistance, and antimicrobial properties to the bamboo. In recent years, many researchers have reported the role of $\mathrm{ZnO}$ nanoparticles in exterior coatings to improve photostability, as a component of UV 
coatings for nanocomposites or modeling UV permeability of nano- $\mathrm{ZnO}$ filled coatings [24-26]. However, there are few reports on treating bamboo with nanomaterials or the effects of the nanomaterials on bamboo durability.

In the present study, the bamboo with multifunction of superhydrophobicity, UV-resistance, and fire-resistance was successfully fabricated by coating with $\mathrm{ZnO}$ nanosheet networks via a hydrothermal method and subsequent modification with FAS-17. The morphologies and chemical compositions were examined by scanning electron microscopy (SEM), energy dispersive spectroscopy (EDS), X-ray diffractometry (XRD), and thermogravimetric and differential thermal analysis (TG-DTA). Water contact angle (WCA) was employed to measure superhydrophobicity of the prepared bamboo surface and the repellency towards simulated acid rain. Meanwhile, the fire-resistance was also illustrated in the paper.

\section{Experimental Section}

2.1. Materials. All the chemicals were purchased from Shanghai Boyle Chemical Company Limited and were all of analytical reagent grade. Bamboo samples of 10 (Length) $\times$ 10 (Width) $\times 4$ (Height) $\mathrm{mm}^{3}$ were cleaned with deionized water and ethanol before drying for use.

2.2. Preparation of $\mathrm{ZnO}$ Sol. The $\mathrm{ZnO}$ sol was prepared based on the method of Jung et al. [27] with some modifications. Zinc acetate dehydrate $(0.75 \mathrm{M})$ was dissolved in ethanol at $60^{\circ} \mathrm{C}$ under vigorous stirring. Then the resulting solution was added slowly to a solution of monoethanolamine (MEA) with volume ratio of $1: 1$ and subsequently stirred at $60^{\circ} \mathrm{C}$ for $0.5 \mathrm{~h}$. The $\mathrm{ZnO}$ sol was thus obtained.

2.3. Growth of ZnO Nanosheet Networks on the Bamboo Surface. Bamboo samples with $\mathrm{ZnO}$ seed layers were fabricated through a simple dip-coating process. Then the samples were dried at $80^{\circ} \mathrm{C}$ for $5 \mathrm{~h}$. This process was repeated 5 times. The growth of $\mathrm{ZnO}$ nanosheet networks on the bamboo substrate was performed as follows: Equimolar aqueous solutions $(0.05 \mathrm{M})$ of zinc nitrate hexahydrate $\left(\mathrm{Zn}\left(\mathrm{NO}_{3}\right)_{2} \cdot 6 \mathrm{H}_{2} \mathrm{O}\right)$ and hexamethylenetetramine $\left(\mathrm{C}_{6} \mathrm{H}_{12} \mathrm{~N}_{4}\right.$, HMTA $)$ were prepared in a vessel under constant stirring, and, then, $0.04 \mathrm{M}$ urea was added. The mixed solution was vigorously stirred for 30 minutes until it became clear and then the clear solution was transferred into a Teflon-lined autoclave. The treated bamboo substrates were then immersed in the above solution for $3 \mathrm{~h}$ at $90^{\circ} \mathrm{C}$. Finally, the samples were rinsed with deionized water and dried at $80^{\circ} \mathrm{C}$ for $24 \mathrm{~h}$. For comparative studies, the blank bamboo samples were also selected and the original bamboo was abbreviated as OB.

2.4. Surface Modification. The surface modification carried out by chemical vapor deposition of FAS-17 was illustrated in Figure 1. The $\mathrm{ZnO}$ nanosheet networks treated bamboo (hereafter abbreviated as ZNB) was placed in a sealed vessel with a smaller unsealed vessel within a small amount of FAS17 on its bottom. The sealed vessel was then put in an oven and heated at $130^{\circ} \mathrm{C}$ to enable the silane groups of FAS-17 vapor to react with the hydroxide groups from $\mathrm{ZNB}$. After $3 \mathrm{~h}$, the bamboo substrate was removed to another clean sealed vessel and heated at $140^{\circ} \mathrm{C}$ for $1 \mathrm{~h}$ to volatilize the residual FAS-17 molecules onto the bamboo substrate. The original bamboo sample modified with FAS-17 was abbreviated as FB. The FAS-17/ZnO nanosheet networks treated bamboo sample was abbreviated as FZNB.

2.5. Characterizations. Surface morphologies of the samples were characterized by scanning electron microscopy (SEM, FEI, Quanta 200). The surface chemical compositions of the samples were determined via energy-dispersive X-ray analysis (EDS, Genesis, EDAX) connected with SEM. Crystalline structures of the samples were identified by X-ray diffraction technique (XRD, Rigaku, D/MAX 2200) operating with $\mathrm{Cu}$ $\mathrm{K} \alpha$ radiation $(\lambda=1.5418 \AA)$ at a scan rate $(2 \theta)$ of $4 \mathrm{~min}^{-1}$, $40 \mathrm{Kv}, 40 \mathrm{~mA}$ ranging from $5^{\circ}$ to $80^{\circ}$. Water contact angle (WCA) was measured on an OCA40 contact angle system (Dataphysics, Germany) at room temperature. The final value of the WCA was obtained as an average of five measurements. Thermogravimetric and differential thermal analysis (TGDTA) were performed using a PE-TGA7 thermogravimetric analyzer (Perkin Elmer Company) and a DTA/9050311 high temperature differential analyzer. $10 \mathrm{mg}$ of the samples were taken and measured in air and then treated in $150 \mathrm{~mL} / \mathrm{min}$ of dry pure $\mathrm{N}_{2}$ with temperatures at the rate of $10^{\circ} \mathrm{C} / \mathrm{min}$ ranging from $20^{\circ} \mathrm{C}$ to $700^{\circ} \mathrm{C}$.

2.6. Accelerated Aging Test. The weathering was performed with an Accelerated Weathering Tester (Q-Panel, Cleveland, $\mathrm{OH}$, USA), which allowed water spray and condensation. The samples were fixed in stainless steel holders and then rotated under irradiation of fluorescent UV light at $60^{\circ} \mathrm{C}$ for $0.5 \mathrm{~h}$, followed by water spraying for $0.5 \mathrm{~h}$ and condensation at $45^{\circ} \mathrm{C}$ for $3 \mathrm{~h}$. The irradiation energy was $35 \mathrm{~W} / \mathrm{m}^{2}$ and the spray temperature $25^{\circ} \mathrm{C}$. The exposure time ranged from $0 \mathrm{~h}$ to $120 \mathrm{~h}$. The color of all samples was determined before and after UV irradiation at regular intervals with a portable spectrophotometer (NF-333, Nippon Denshoku Company, Japan) equipped with a CIE- $L A B$ system. Here, the parameters represent $L^{*}, a^{*}$, and $b^{*}$ lightness, which varies from 100 (white) to 0 (black) and chromaticity indices $\left(+a^{*}\right.$ red, $-a^{*}$ green, $+b^{*}$ yellow, and $-b^{*}$ blue).

The changes in $L^{*}, a^{*}$, and $b^{*}$ were calculated according to (1), as follows:

$$
\begin{gathered}
\Delta a^{*}=a_{2}-a_{1}, \\
\Delta b^{*}=b_{2}-b_{1}, \\
\Delta L^{*}=L_{2}-L_{1},
\end{gathered}
$$

where $\Delta$ means the difference between the indicated initial and final parameters after UV irradiation. The overall color changes $\left(\Delta E^{*}\right)$ were used to evaluate the total color change using (2). Consider

$$
\Delta E^{*}=\left(\left(L_{2}^{*}-L_{1}^{*}\right)^{2}+\left(a_{2}^{*}-a_{1}^{*}\right)^{2}+\left(b_{2}^{*}-b_{1}^{*}\right)^{2}\right)^{1 / 2} .
$$




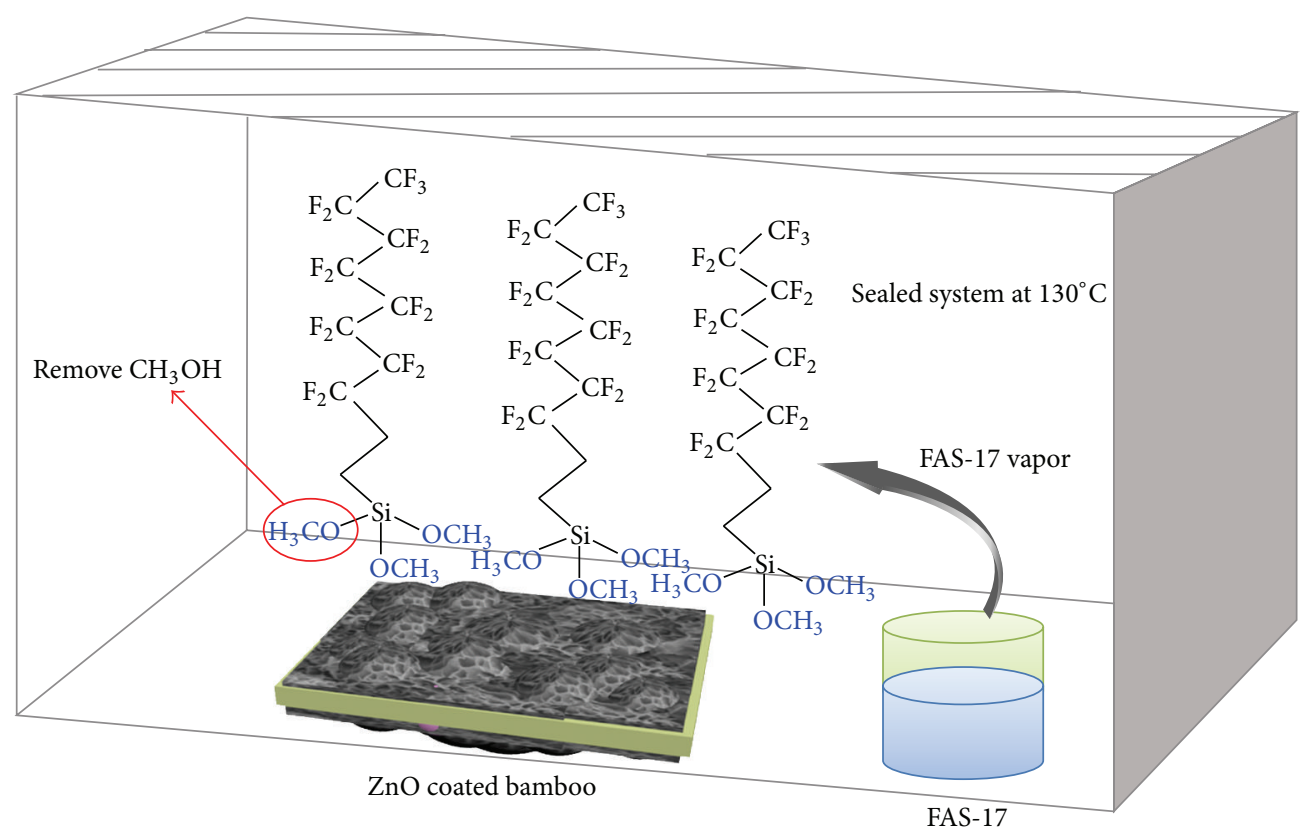

FIGURE 1: Schematic illustration of the surface modification on $\mathrm{ZnO}$-coated bamboo surface.

A lower $\Delta E^{*}$ value corresponds to a smaller color difference and indicates strong resistance to UV radiation. CIE$L^{*}, a^{*}, b^{*}$, and $\Delta E$ were measured at five locations on each sample, and the average values were calculated.

\section{Results and Discussion}

3.1. Characterization of $\mathrm{ZnO}$ Nanosheet Networks. SEM images were used to illustrate the morphology of $O B$ and ZNB. As shown in Figure 2(a), the SEM image of OB showed smooth and clean surface. In Figure 2(b), the $\mathrm{ZnO}$ nanosheet networks appeared on the bamboo substrate and the bamboo surface became rougher in a result of coating with a dense film of $\mathrm{ZnO}$ nanostructured materials. In the magnified SEM image (Figure 2(c)), the $\mathrm{ZnO}$ nanosheet networks were slightly curved and the surface seemed to be uneven on a large scale. The average width and height for observation of the $\mathrm{ZnO}$ nanosheets was about $80 \mathrm{~nm}$ and $3 \mu \mathrm{m}$, respectively. The surface chemical elemental compositions of the ZNB were determined via EDS, and the results are presented as an insertion in Figure 2(b). Only carbon, oxygen, zinc, and gold elements could be detected from the EDS spectrum. Gold element was from the coating layer used for the EDS measurement and carbon element was originated from the bamboo substrates. No other elements were detected, confirming that the pure $\mathrm{ZnO}$ nanosheet networks were effectively formed on the bamboo surface. In Figure 2(d), the diffraction peaks at $16^{\circ}$ and $22^{\circ}$ represented the characteristic diffraction peaks of the cellulose from bamboo substrate [28, 29]. All others diffraction peaks could be indexed to the wurtzite $\mathrm{ZnO}$ (JCPDS card No. 36-1451). No other characteristic peaks were observed, indicating that pure wurtzite $\mathrm{ZnO}$ were formed on the bamboo surface after the hydrothermal process.
3.2. WCAs Test. With hydroxyl groups covering the surface, the $\mathrm{OB}$ was intrinsically hydrophilic and the water would fastly wet the surface, so WCAs were measured as soon as the water droplets contacted the samples surface. However, for the FB and FZNB, WCAs were achieved after contacted with the surfaces for $5 \mathrm{~min}$. As shown in Figure 3, the WCA of $\mathrm{OB}$ was $12^{\circ}$ for $5 \mu \mathrm{L}$ water droplet, after modification with FAS-17, the FB became hydrophobicity with the WCA of $126^{\circ}$, and the FZNB was superhydrophobic with the WCA of $161^{\circ}$. As the results showed, both the surface energy and surface roughness deeply affected the degree of hydrophobicity of the surface, which was represented as water contact angle. The sliding angle of the FZNB was lower than $3^{\circ}$, indicating the water droplets could roll off the surface easily. Besides the excellent superhydrophobicity, FZNB exhibited stable repellency towards simulated acid rain $(\mathrm{pH}=3)$ with a contact angle of $152^{\circ}$ (Figure 3(d)). Thus, such an as-prepared surface would have the anticorrosion property against acid rain in the atmosphere environment.

A further understanding of the hydrophobicity of asprepared samples could be obtained from the Cassie-Baxter equation, $\cos \theta_{r}=f_{1} \cos \theta-f_{2} . \theta_{r}$ was the apparent contact angle measured on the interested bamboo surface; $\theta\left(100^{\circ}\right)$ was the water contact angle on fluoridated smooth surface [30]; $f_{1}$ and $f_{2}$ were the fractional areas estimated for the solid and air on the surface, respectively; that is, $f_{1}+f_{2}=1$. Here, the CA value of $\mathrm{FB}$ was $126^{\circ}\left(\theta_{r}\right)$ and the $f_{1}$ calculated using Cassie-Baxter equation was 0.49 , which indicated that $51 \%$ of the surface was occupied by air. However, for FZNB $\left(\theta_{r}=161^{\circ}\right)$, the $f_{1}$ was 0.05 , which indicated that about $95 \%$ of the surface was occupied by air. The surface allowed air to be trapped more easily underneath the water droplets, 


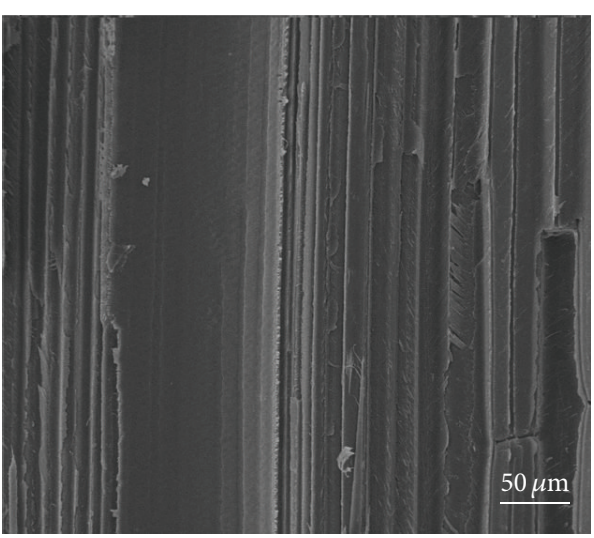

(a)

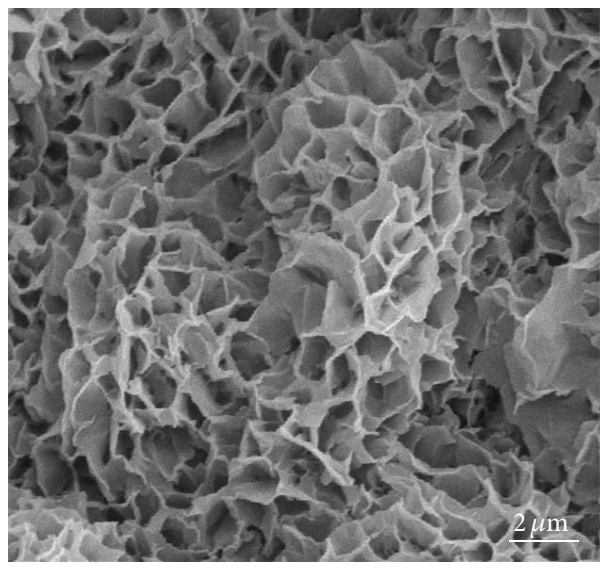

(c)

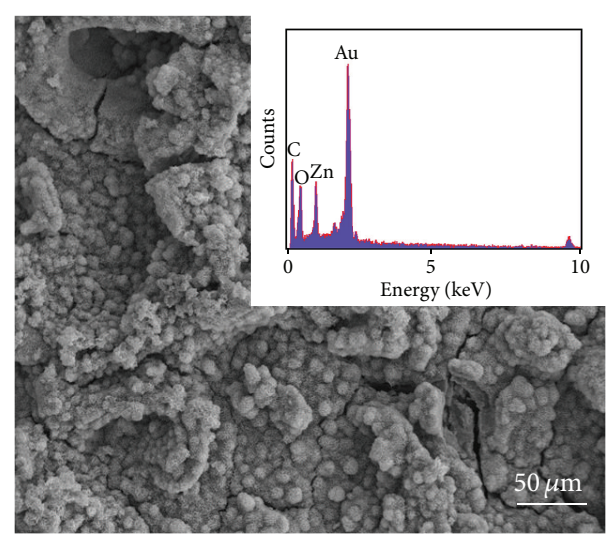

(b)

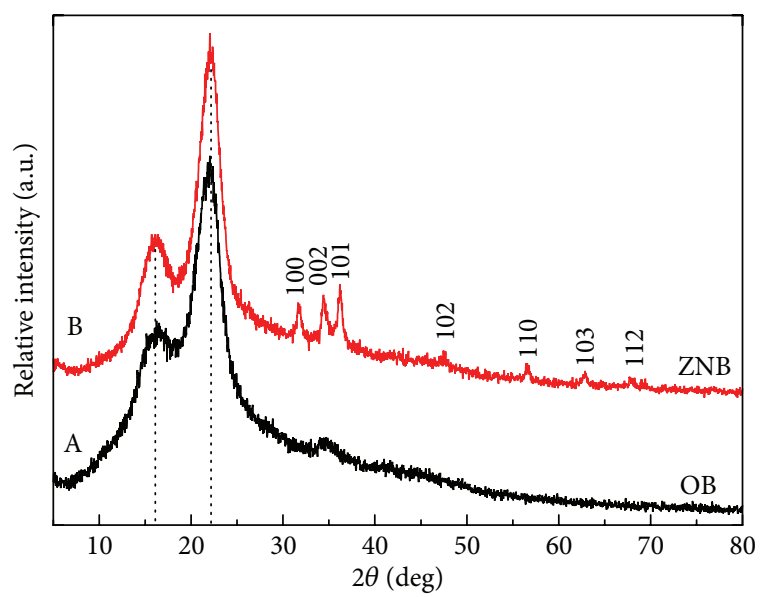

(d)

FIGURE 2: SEM images of (a) OB and ZNB at low (b) and high (c) magnification. The inset of (b) was EDS spectrum of ZNB. (d) XRD patterns of $\mathrm{OB}$ and $\mathrm{ZNB}$, respectively.

so that the water droplets essentially rested on a layer of air. Therefore, WCAs of the FZNB increased significantly.

Except for superhydrophobicity, the FZNB showed a low adhesion to water. The water droplet could hardly stick to the bamboo surface, allowing water droplets to roll off from one side of the surface freely (Figure 4(a)). As the descent height of the water droplet increased, it could bounce up from the bamboo surface without any deformation (Figure 4(b)). In addition, the WCA values of the as-prepared surfaces were constant after storage for more than six months under ambient conditions. These performances confirmed the stable superhydrophobicity of FZNB under ambient conditions.

3.3. Water Absorption Properties. Water absorption is one of the most important characteristics of bamboo exposed to environmental conditions that determines their ultimate applications. In this study, the water resistance of the OB, FB, and FZNB was investigated. The experiments were carried out by immersing as-prepared specimens in water for $130 \mathrm{~h}$ at room temperature, followed by measuring the moisture content $(\%)$ and WCA $\left(^{\circ}\right)$ of the as-prepared specimens.
The moisture content of specimen was calculated by the following equation:

moisture content (\%)

$$
=\frac{\text { weight of specimen }- \text { weight of dry specimen }}{\text { weight of dry specimen }},
$$

where the weight of dry specimen was obtained by drying bamboo specimen at $105^{\circ} \mathrm{C}$ until a constant weight was obtained.

As shown in Figure 5, it was found that the moisture content of the FZNB increased to $80 \%$ after the specimen was fully immersing in water for $24 \mathrm{~h}$. After the specimen was fully immersing in water for $130 \mathrm{~h}$, the moisture content of the FZNB was still around $80 \%$, whereas the OB specimen and the FB specimen could absorb up to $180 \%$ and $200 \%$ water, respectively. After $24 \mathrm{~h}$ immersion, the moisture content of the $\mathrm{FB}$ was higher than that of the $\mathrm{OB}$, which might due to the FAS-17 coated on the surface of $\mathrm{OB}$ be further hydrolyzed in water following the increasing time of immersion. It was also found that WCA of the FZNB maintained $152^{\circ}$ after immersing in water for $130 \mathrm{~h}$ (Figure 5, inset), which 


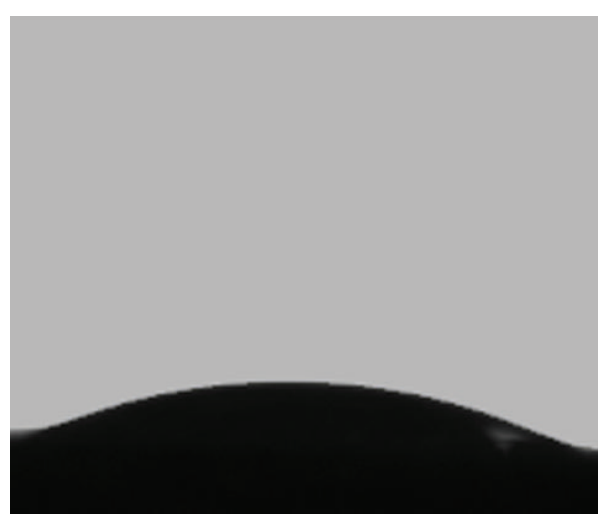

(a)

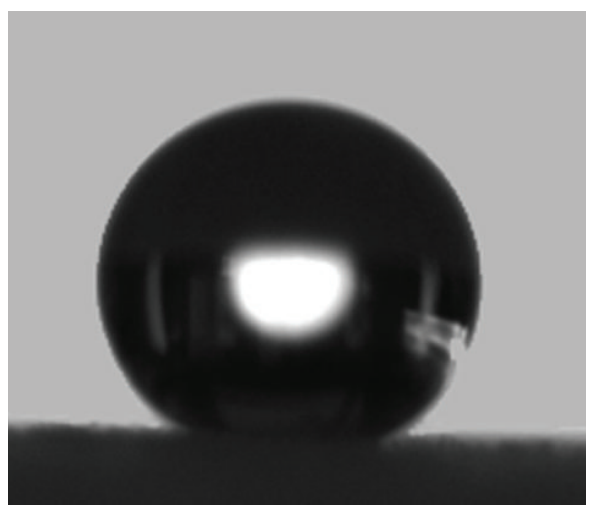

(c)

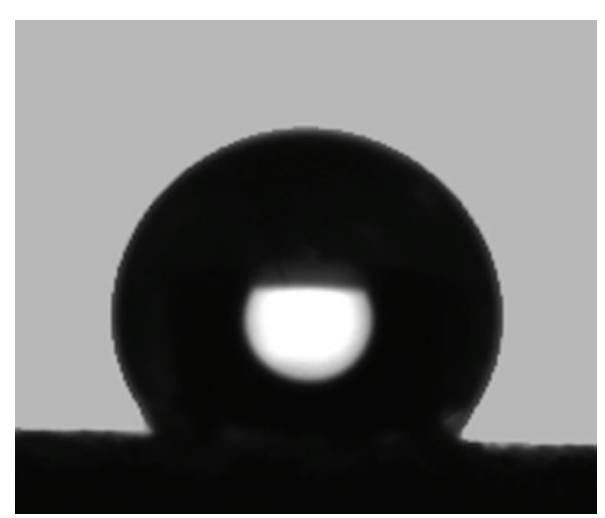

(b)

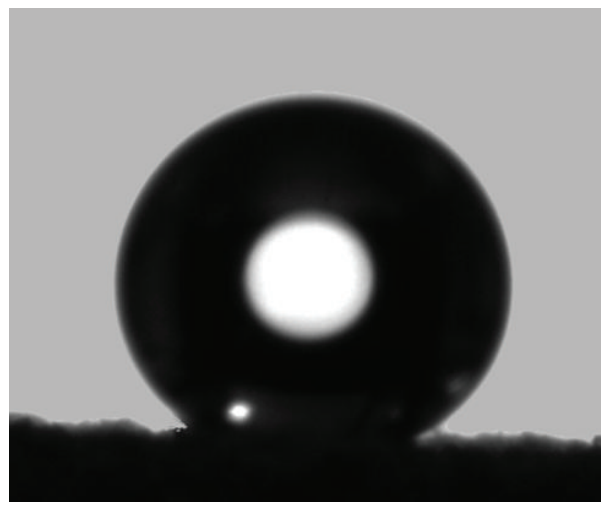

(d)

FIGURE 3: Shapes of water droplet on (a) OB, (b) FB, and (c) FZNB, respectively. (d) Shape of simulated acid rain (pH = 3) on FZNB.

demonstrated that the extremely high water resistance of the FZNB was obtained. The performance of the water resistance verified the FZNB would be a great potential for the applications in the environment with higher moist.

3.4. UV Resistance Study. The experimental results of color change upon UV irradiation were presented in Figure 6. Compared to $\mathrm{OB}$, the $\Delta L^{*}$ value of the FZNB sample became positive, indicating that the light-colored bamboo turned white (Figure 6(a)). On the other hand, the $\Delta L^{*}$ value of the $\mathrm{OB}$ became negative, indicating that the light-colored bamboo turned black. The $\Delta b^{*}$ value of the OB and FZNB specimens indicated that the surfaces colors turned dark yellow and slight yellow, respectively, with prolonged UV irradiation time (Figure 6(b)). More importantly, the $\Delta a^{*}$ value of the $\mathrm{OB}$ under $\mathrm{UV}$ irradiation indicated that the surface color turned a deeper shade of red with increasing UV irradiation. The $\Delta a^{*}$ of the FZNB sample showed a similar trend; however, the change in the FZNB $\Delta a^{*}$ was much smaller than that of $\mathrm{OB}$ (Figure 6(c)). The total color change $\left(\Delta E^{*}\right)$ of $\mathrm{OB}$ was significant (Figure $6(\mathrm{~d})$ ), whereas for the FZNB was very slight. These results showed that FZNB exhibited an excellent UV resistance and prevented bamboo surface from damage.

3.5. Thermal Stability. The results of the TG-DTA analysis were shown in Figure 7. According to the TG curve
(Figure 7(a)), there was a small weight loss at about 50$80^{\circ} \mathrm{C}$ due to the loss of physically adsorbed water, which come from the ambient environment [31]. The three stages of the thermal degradation of the $\mathrm{OB}$ were clearly visible. At stage one $\left(190-250^{\circ} \mathrm{C}\right)$, the pyrolysis rate was low with the weight loss of approximately $13 \%$, which is mainly due to the partial degradation of hemicellulose [32]. Stage two $\left(250-400^{\circ} \mathrm{C}\right)$ was mainly caused by cellulose degradation, accompanied with continuous degradation of lignin, whose maximum pyrolysis rate occurred at $375^{\circ} \mathrm{C}$ and the weight loss reached $68 \%$ [33]. At stage three $\left(400-700^{\circ} \mathrm{C}\right)$, all the components of bamboo degraded gradually leading to aromatization and carbonization. Lignin was the most difficult one to decompose. Its decomposition happened slowly and kept on along the whole calcining process $[34,35]$. At last, carbon residues with the weight of $8.9 \%$ were left, as observed from the TG curve (Figure 7(a)). For the ZNB and FZNB specimens, the TG curve exhibited the weight losses at about $170-240^{\circ} \mathrm{C}$, which were caused by the decomposition of the residual organics and MEA $[36,37]$. And the DTA curve (Figure $7(\mathrm{~b})$ ) presented strong and sharp endothermic peaks at a minimum of $356^{\circ} \mathrm{C}$ for $\mathrm{ZNB}$ and $347^{\circ} \mathrm{C}$ for CZNB, respectively, corresponding to the weight losses shown in the TG curve (Figure 7(a)). Due to the decomposition of cellulose and lignin, the maximum degradation rates of the ZNB and FZNB became lower than of the OB. This might be due to the catalysis of $\mathrm{ZnO}$, which generated an accelerated pyrolysis 

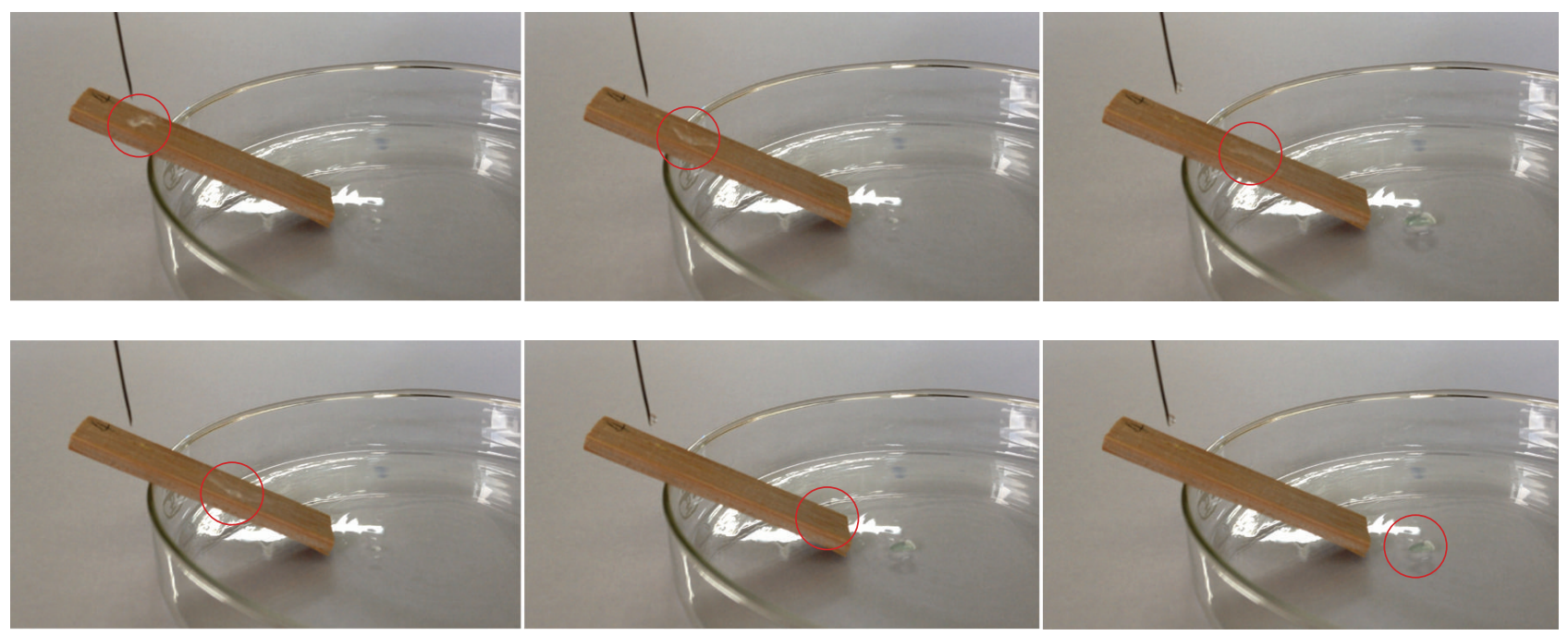

(a)
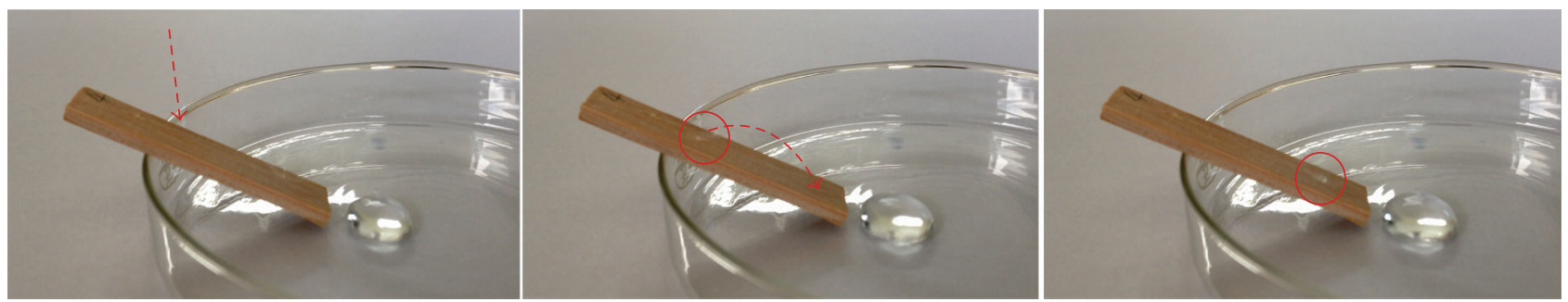

(b)

FIGURE 4: The rolling process of a water droplet on the superhydrophobic bamboo surface.

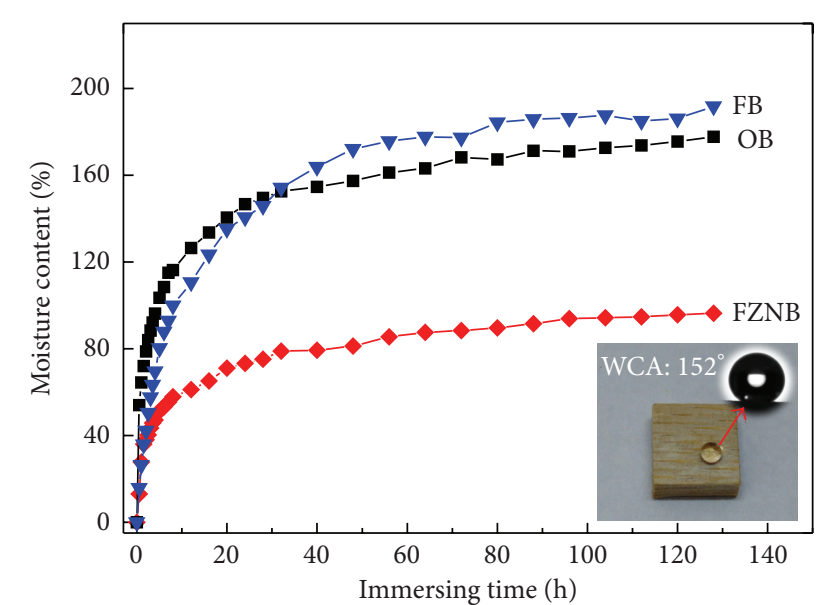

Figure 5: Moisture content of OB, FB, and FZNB, respectively. The inset was the WCA of FZNB after immersing in water to $130 \mathrm{~h}$.

action on bamboo components. Moreover, the maximum degradation rate of the FZNB was the lowest (Figure 7(b)), which might be due to the decomposition of FAS-17 (a barrier effectively protected for the ZNB). Computable weight loss along the whole process was about $91.1 \%$ for OB, $78.3 \%$ for $\mathrm{ZNB}$, and $73.2 \%$ for FZNB, respectively.
3.6. Fire-Resistant Properties. In order to describe a realistic fire scenario, it was important to test the ignitability of the $\mathrm{OB}$ and FZNB samples in the presence of a flame spread. Interestingly, the as-prepared FZNB sample exhibited excellent fire-resistance when exposed to the flame of the alcohol burner. A significant difference could be observed in Figure 8 where some typical pictures of the specimens after the flammability test were collected. When heated with the alcohol burner, the $\mathrm{OB}$ caught on fire at $3 \mathrm{~s}$ and was incinerated to ash in $101 \mathrm{~s}$. Being burned for $24 \mathrm{~s}$, the OB sample had a massive blaze. In the following $34 \mathrm{~s}$, the strong flames gradually diminished, but the fire was still spreading. By contrast, the FZNB caught on fire at $16 \mathrm{~s}$, implying that the FAS-17/ZnO films were capable of protecting the bamboo from the flame. Being burned for $46 \mathrm{~s}$, there were no flames standing on the treated bamboo sample. Furthermore, the flames gradually quenched by itself in the following $2 \mathrm{~s}$. After burning out, black char was left. Apparently, the treated bamboo samples were more suitable for functional materials and building materials.

\section{Conclusions}

In this paper, bamboo with multifunction involved in waterresistant, UV-resistant, and fire-resistant properties was 


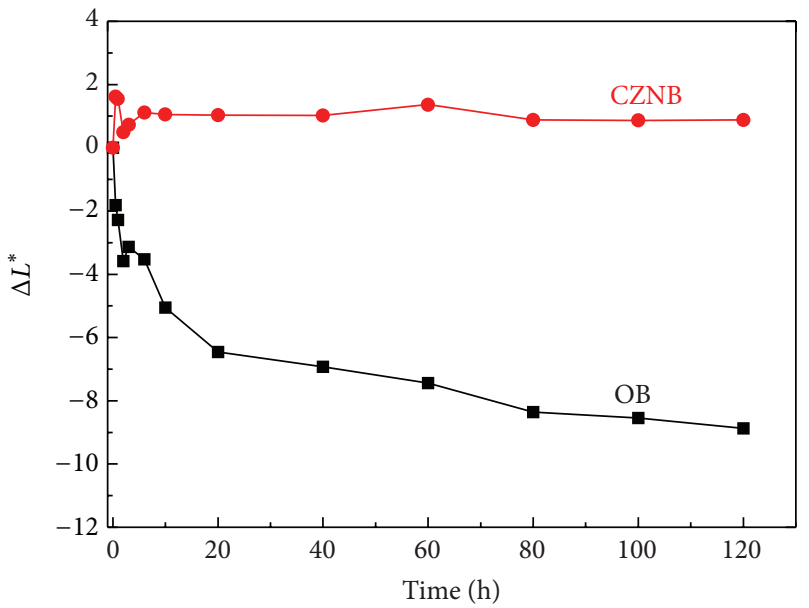

(a)

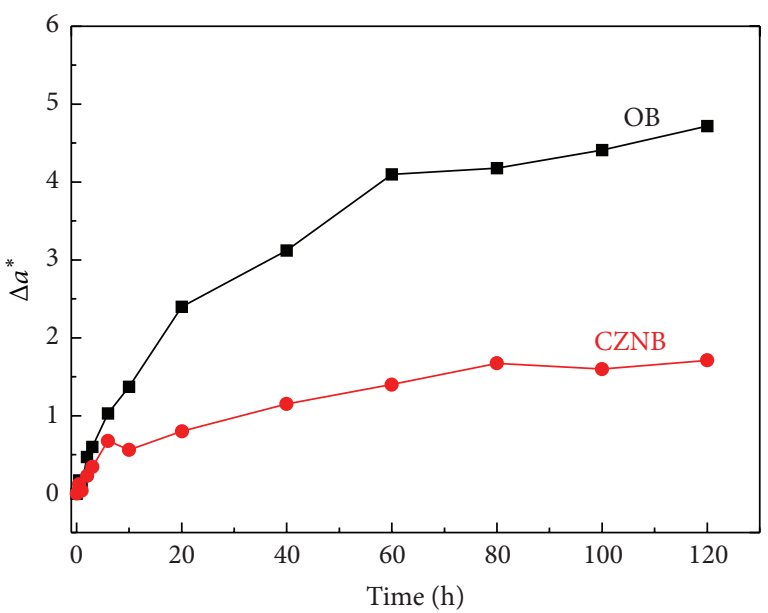

(c)

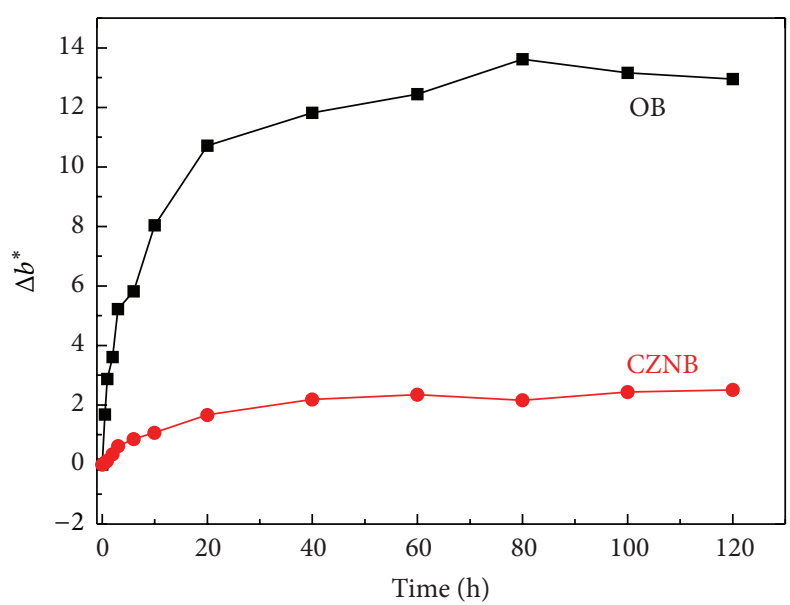

(b)

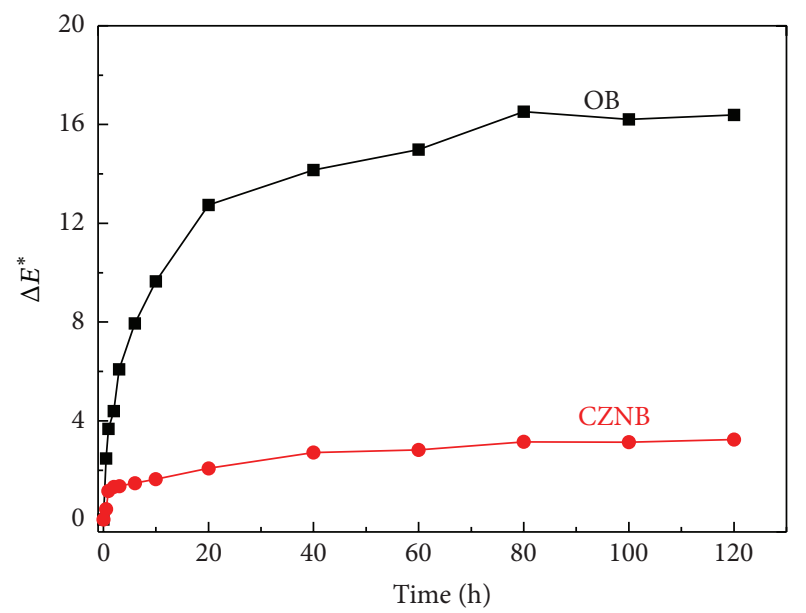

(d)

Figure 6: Color data of CIE- $L^{*}, a^{*}$, and $b^{*}$ and $\Delta E^{*}$ measurements of OB and CZNB samples, respectively.

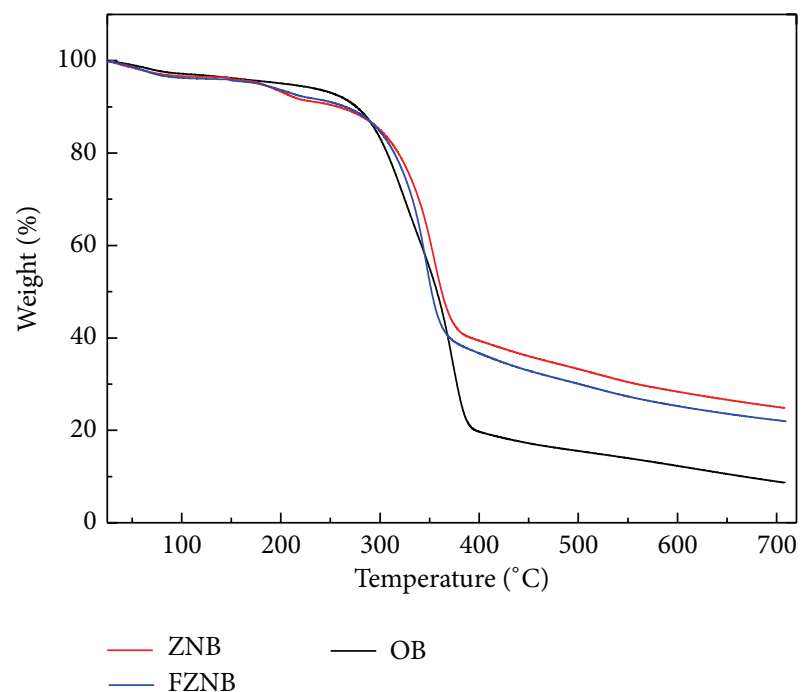

(a)

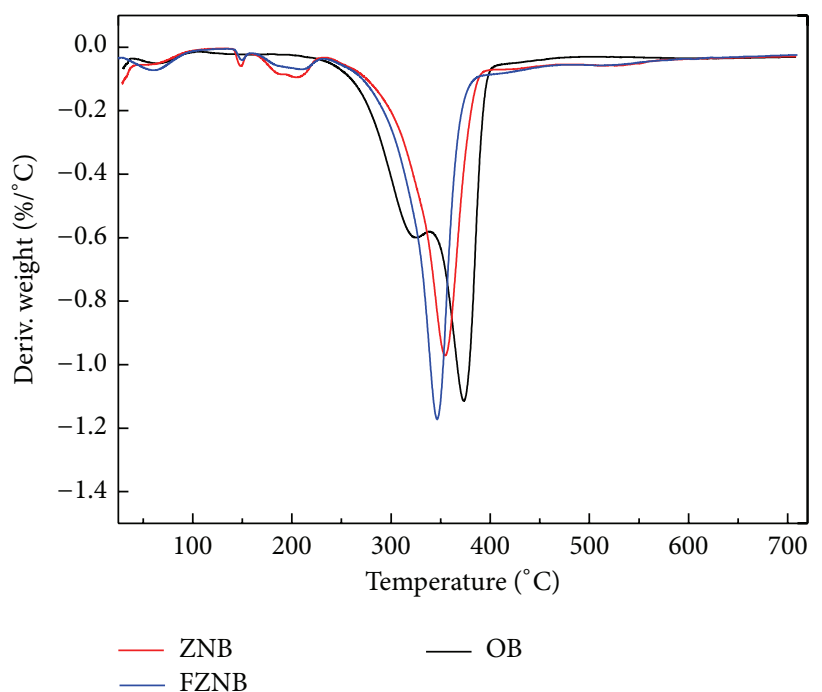

(b)

FIgURE 7: TG-DTA curves of OB, ZNB, and FZNB, respectively. 


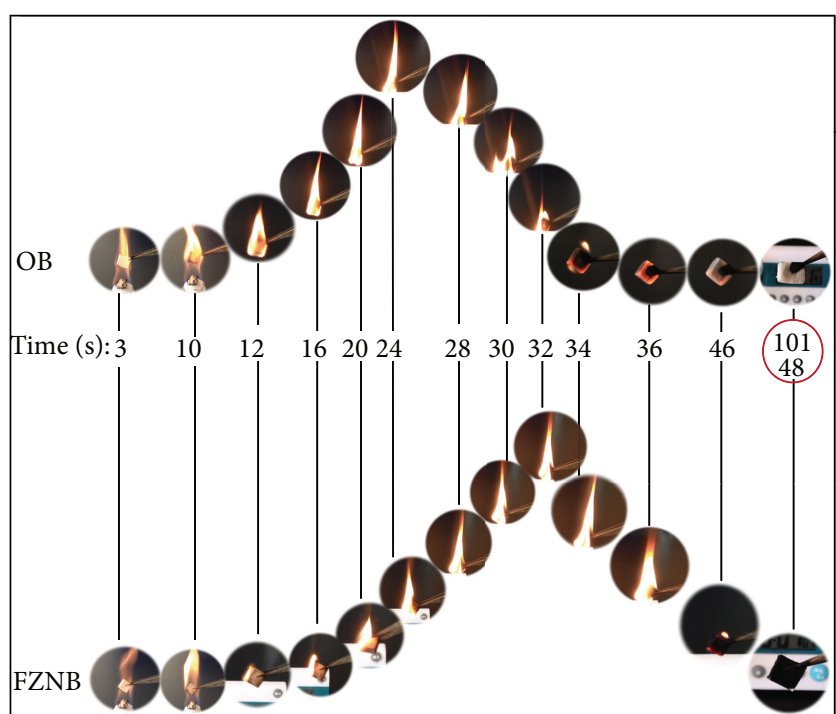

FIGURE 8: Digital photos of OB and FZNB burned at different times, respectively (the as-prepared samples firstly were all heated in an alcohol burner for $12 \mathrm{~s}$ ).

successfully fabricated by $\mathrm{ZnO}$ nanosheet networks deposition, followed by a fluorination treatment. The treated bamboo substrate exhibited not only robust superhydrophobicity but also stable repellency towards simulated acid rain $(\mathrm{pH}=3)$. Furthermore, the treated bamboo presented excellent water-resistant and UV-resistant properties and also exhibited superior fire-resistant property.

\section{Conflict of Interests}

The authors declare that there is no conflict of interests regarding the publication of this paper.

\section{Acknowledgments}

The work was financially supported by the National Natural Science Foundation of China (31470586) and Pre-research Project of Research Center of Biomass Resource Utilization, Zhejiang A \& F University (2013SWZ01-03).

\section{References}

[1] Z. Peng, Y. Lu, L. Li et al., "The draft genome of the fastgrowing non-timber forest species moso bamboo (Phyllostachys heterocycla)," Nature Genetics, vol. 45, no. 4, pp. 456-461, 2013.

[2] M.-J. Chung, S.-S. Cheng, C.-J. Lee, and S.-T. Chang, "Novel environmentally-benign methods for green-colour protection of bamboo culms and leaves," Polymer Degradation and Stability, vol. 96, no. 4, pp. 541-546, 2011.

[3] Y. Onozawa, M. Chiwa, H. Komatsu, and K. Otsuki, "Rainfall interception in a moso bamboo (Phyllostachys pubescens) forest," Journal of Forest Research, vol. 14, no. 2, pp. 111-116, 2009.

[4] X.-Q. Wang and H.-Q. Ren, "Surface deterioration of moso bamboo (Phyllostachys pubescens) induced by exposure to artificial sunlight," Journal of Wood Science, vol. 55, no. 1, pp. 47-52, 2009.
[5] X. Wang and H. Ren, "Comparative study of the photodiscoloration of moso bamboo (Phyllostachys pubescens Mazel) and two wood species," Applied Surface Science, vol. 254, no. 21, pp. 7029-7034, 2008.

[6] K.-C. Hung, Y.-L. Chen, and J.-H. Wu, "Natural weathering properties of acetylated bamboo plastic composites," Polymer Degradation and Stability, vol. 97, no. 9, pp. 1680-1685, 2012.

[7] K.-T. Lu, "Effects of hydrogen peroxide treatment on the surface properties and adhesion of ma bamboo (Dendrocalamus latiflorus)," Journal of Wood Science, vol. 52, no. 2, pp. 173-178, 2006.

[8] S.-T. Chang, T.-F. Yeh, and J.-H. Wu, "Mechanisms for the surface colour protection of bamboo treated with chromated phosphate," Polymer Degradation and Stability, vol. 74, no. 3, pp. 551-557, 2001.

[9] M. Dunlap, "Protection wood from moisture," Industrial \& Engineering Chemistry, vol. 18, no. 12, pp. 1230-1232, 1926.

[10] Y. Lu, S. Xiao, R. Gao, J. Li, and Q. Sun, "Improved weathering performance and wettability of wood protected by $\mathrm{CeO}_{2}$ coating deposited onto the surface," Holzforschung, vol. 68, no. 3, pp. 345-351, 2014.

[11] Q. Sun, H. Yu, Y. Liu, J. Li, Y. Cui, and Y. Lu, "Prolonging the combustion duration of wood by $\mathrm{TiO}_{2}$ coating synthesized using cosolvent-controlled hydrothermal method," Journal of Materials Science, vol. 45, no. 24, pp. 6661-6667, 2010.

[12] J. R. Loferski, “Technologies for wood preservation in historic preservation," Archives and Museum Informatics, vol. 13, no. 3-4, pp. 273-290, 1999.

[13] Q. Sun, H. Yu, Y. Liu, J. Li, Y. Lu, and J. F. Hunt, "Improvement of water resistance and dimensional stability of wood through titanium dioxide coating," Holzforschung, vol. 64, no. 6, pp. 757761, 2010.

[14] L. Wang, X. Zhang, B. Li et al., "Superhydrophobic and ultraviolet-blocking cotton textiles," ACS Applied Materials \& Interfaces, vol. 3, no. 4, pp. 1277-1281, 2011.

[15] O. Starkova, S. Chandrasekaran, L. A. S. A. Prado, F. Tölle, R. Mülhaupt, and K. Schulte, "Hydrothermally resistant thermally reduced graphene oxide and multi-wall carbon nanotube based epoxy nanocomposites," Polymer Degradation and Stability, vol. 98, no. 2, pp. 519-526, 2013.

[16] Y. Yu, Z. Jiang, G. Wang, G. Tian, H. Wang, and Y. Song, "Surface functionalization of bamboo with nanostructured ZnO," Wood Science and Technology, vol. 46, no. 4, pp. 781-790, 2012.

[17] T. Kuwabara, Y. Kawahara, T. Yamaguchi, and K. Takahashi, "Characterization of inverted-type organic solar cells with a $\mathrm{ZnO}$ layer as the electron collection electrode by ac impedance spectroscopy," ACS Applied Materials and Interfaces, vol. 1, no. 10, pp. 2107-2110, 2009.

[18] B.-Y. Oh, M.-C. Jeong, T.-H. Moon et al., "Transparent conductive Al-doped $\mathrm{ZnO}$ films for liquid crystal displays," Journal of Applied Physics, vol. 99, no. 12, Article ID 124505, 2006.

[19] X. Wang, W. Liu, J. Liu et al., "Synthesis of nestlike $\mathrm{ZnO}$ hierarchically porous structures and analysis of their gas sensing properties," ACS Applied Materials and Interfaces, vol. 4, no. 2, pp. 817-825, 2012.

[20] K. Mukae, K. Tsuda, and I. Nagasawa, "Capacitance-vs-voltage characteristics of $\mathrm{ZnO}$ varistors," Journal of Applied Physics, vol. 50, no. 6, pp. 4475-4476, 1979.

[21] B. J. M. Velazquez, S. Baskaran, A. V. Gaikwad et al., "Effective piezoelectric response of substrate-integrated $\mathrm{ZnO}$ nanowire 
array devices on galvanized steel," ACS Applied Materials \& Interfaces, vol. 5, no. 21, pp. 10650-10657, 2013.

[22] L. Luo, Y. Zhang, S. S. Mao, and L. Lin, "Fabrication and characterization of $\mathrm{ZnO}$ nanowires based UV photodiodes," Sensors and Actuators A: Physical, vol. 127, no. 2, pp. 201-206, 2006.

[23] O. Lupan, T. Pauporté, B. Viana, I. M. Tiginyanu, V. V. Ursaki, and $\mathrm{R}$. Cortès, "Epitaxial electrodeposition of $\mathrm{ZnO}$ nanowire arrays on $\mathrm{p}-\mathrm{GaN}$ for efficient UV-light-emitting diode fabrication," ACS Applied Materials and Interfaces, vol. 2, no. 7, pp. 2083-2090, 2010.

[24] M. Beyer, F. Weichelt, R. Emmler, R. Flyunt, E. Beyer, and M. R. Buchmeiser, "ZnO-based UV nanocomposites for wood coatings in outdoor applications," Macromolecular Materials and Engineering, vol. 295, no. 2, pp. 130-136, 2010.

[25] R. R. Devi and T. K. Maji, "Effect of Nano-ZnO on thermal, mechanical, UV stability, and other physical properties of wood polymer composites," Industrial and Engineering Chemistry Research, vol. 51, no. 10, pp. 3870-3880, 2012.

[26] C. Hegedus, F. Pepe, D. Lindenmuth, and D. Burgard, "Zinc oxide nanoparticle dispersion as unique additives for coatings," JCT CoatingsTech, vol. 5, no. 4, pp. 42-52, 2008.

[27] H. J. Jung, S. Lee, Y. Yu, S. M. Hong, H. C. Choi, and M. Y. Choi, "Low-temperature hydrothermal growth of $\mathrm{ZnO}$ nanorods on sol-gel prepared $\mathrm{ZnO}$ seed layers: optimal growth conditions," Thin Solid Films, vol. 524, pp. 144-150, 2012.

[28] J. Li, Y. Lu, D. Yang, Q. Sun, Y. Liu, and H. Zhao, "Lignocellulose aerogel from wood-ionic liquid solution (1-allyl3-methylimidazolium chloride) under freezing and thawing conditions," Biomacromolecules, vol. 12, no. 5, pp. 1860-1867, 2011.

[29] Y. Lu, Q. Sun, D. Yang et al., "Fabrication of mesoporous lignocellulose aerogels from wood via cyclic liquid nitrogen freezing-thawing in ionic liquid solution," Journal of Materials Chemistry, vol. 22, no. 27, pp. 13548-13557, 2012.

[30] H. Yang and Y. Deng, "Preparation and physical properties of superhydrophobic papers," Journal of Colloid and Interface Science, vol. 325, no. 2, pp. 588-593, 2008.

[31] E. Ahmad and A. Luyt, "Effects of organic peroxide and polymer chain structure on morphology and thermal properties of sisal fibre reinforced polyethylene composites," Composites Part A: Applied Science and Manufacturing, vol. 43, no. 4, pp. 703-710, 2012.

[32] X. Li, B. Lei, Z. Lin, L. Huang, S. Tan, and X. Cai, "The utilization of bamboo charcoal enhances wood plastic composites with excellent mechanical and thermal properties," Materials and Design, vol. 53, pp. 419-424, 2014.

[33] H. Essabir, E. Hilali, A. Elgharad et al., "Mechanical and thermal properties of bio-composites based on polypropylene reinforced with Nut-shells of Argan particles," Materials and Design, vol. 49, pp. 442-448, 2013.

[34] H. Yang, R. Yan, H. Chen, D. H. Lee, and C. Zheng, "Characteristics of hemicellulose, cellulose and lignin pyrolysis," Fuel, vol. 86, no. 12-13, pp. 1781-1788, 2007.

[35] H. Yang, R. Yan, H. Chen, C. Zheng, D. H. Lee, and D. T. Liang, "In-depth investigation of biomass pyrolysis based on three major components: hemicellulose, cellulose and lignin," Energy and Fuels, vol. 20, no. 1, pp. 388-393, 2006.

[36] D. Raoufi and T. Raoufi, "The effect of heat treatment on the physical properties of sol-gel derived $\mathrm{ZnO}$ thin films," Applied Surface Science, vol. 255, no. 11, pp. 5812-5817, 2009.
[37] J.-H. Lee, K.-H. Ko, and B.-O. Park, "Electrical and optical properties of $\mathrm{ZnO}$ transparent conducting films by the sol-gel method," Journal of Crystal Growth, vol. 247, no. 1-2, pp. 119-125, 2003. 

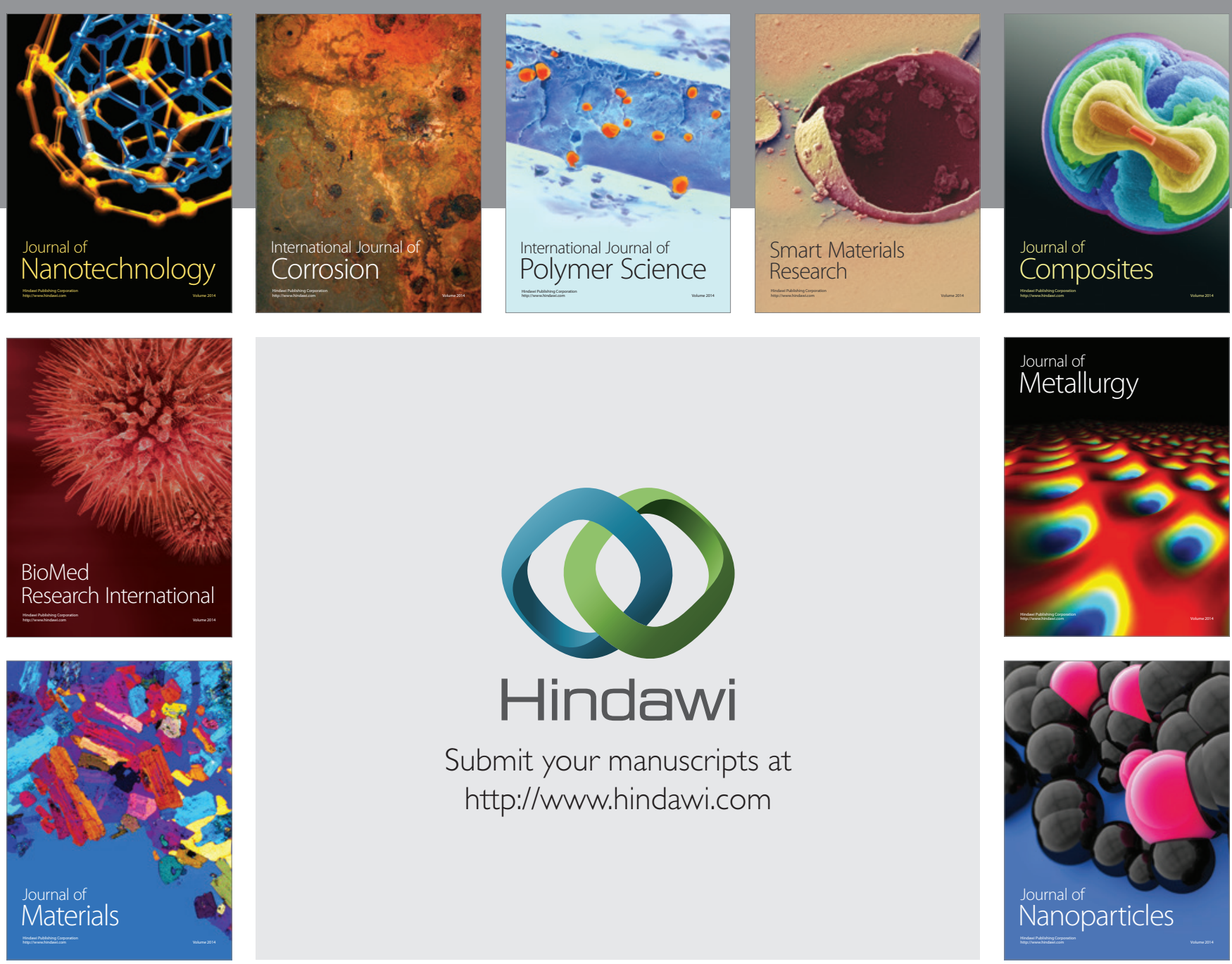

Submit your manuscripts at http://www.hindawi.com
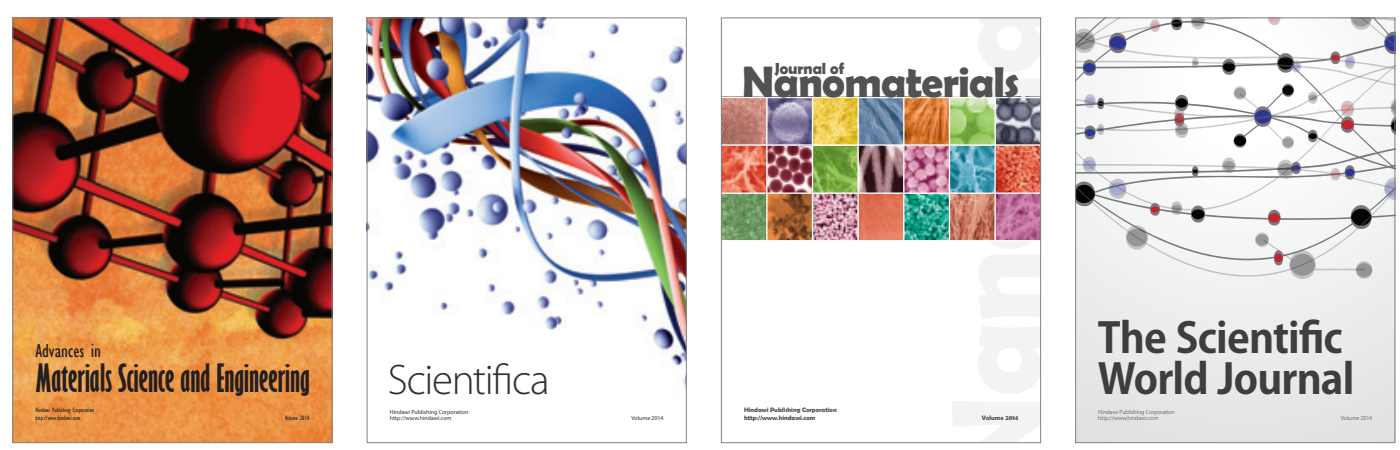

\section{The Scientific World Journal}
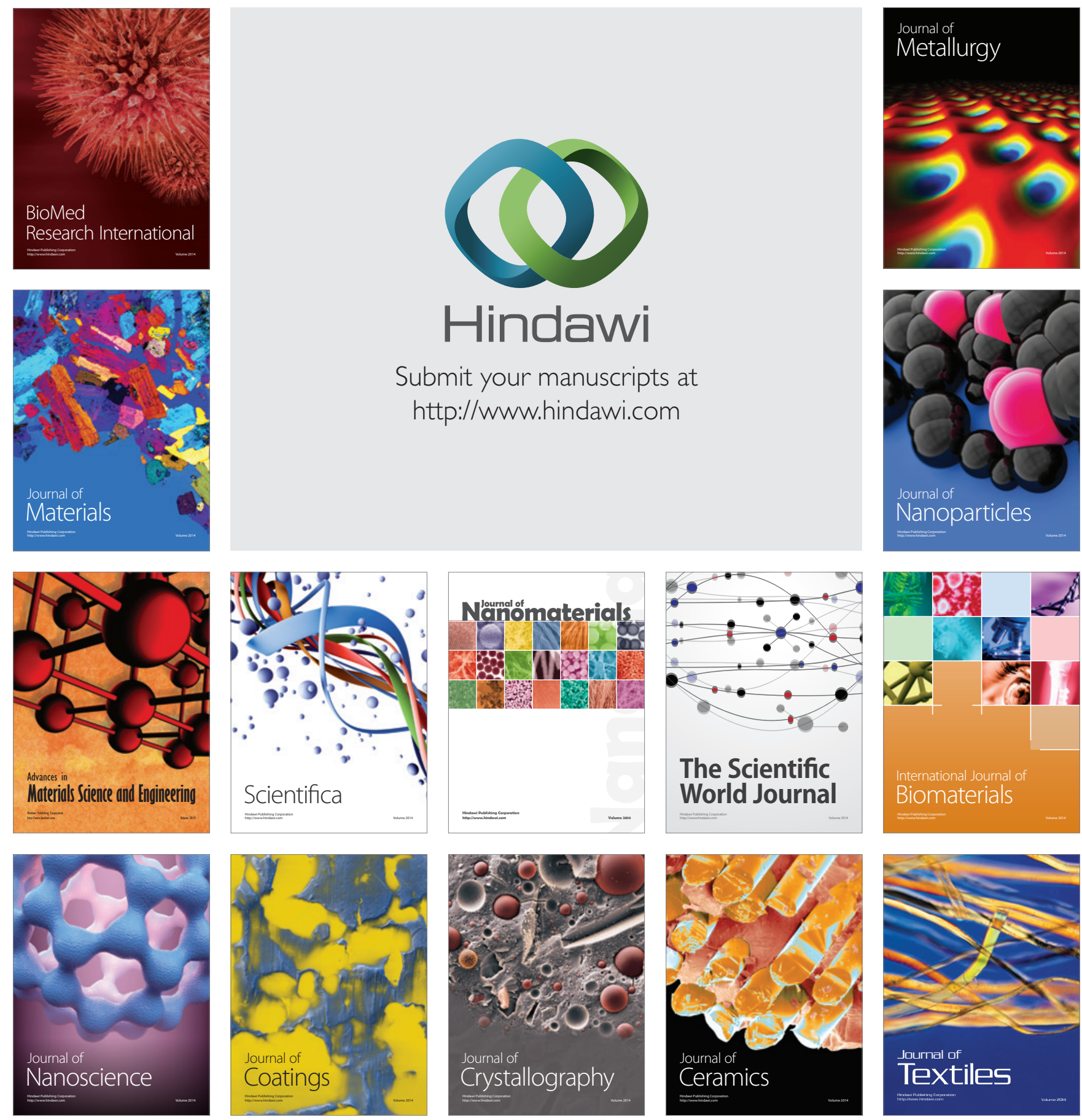